\title{
Formulation and Implementation of Energy Efficient Ultraviolet Curing for Photosensitive Resin-Bound Diamond Wire Saws
}

\author{
Chunyan Yao, Wei Peng, and Fuqing Liu \\ Key Laboratory of E\&M Zhejiang University of Technology, Ministry of Education \& Zhejiang Province, Hangzhou 310023, China \\ Correspondence should be addressed to Wei Peng; pengwei@zjut.edu.cn
}

Received 3 January 2013; Revised 10 March 2013; Accepted 2 April 2013

Academic Editor: Shengyong Chen

Copyright (C) 2013 Chunyan Yao et al. This is an open access article distributed under the Creative Commons Attribution License, which permits unrestricted use, distribution, and reproduction in any medium, provided the original work is properly cited.

\begin{abstract}
It is a currently dominant method to use wire saws for cutting silicon material because of its production efficiency and energy efficiency. Diamond wire saws, or fixed abrasive wire saws, have attracted much attention to researchers and engineers due to many advantages, including high cutting efficiency and low environmental pollution. This paper develops a novel diamond wire saw using ultraviolet curing technology. High-strength piano wires and polyethylene wires are selected as wire cores, and photosensitive resin is used as the binder. The problem of wire saw strength is mathematically formulated, and the effective parameters are analyzed. The surface morphology is analyzed for the developed diamond wire saw. A series of cutting experiments with different saws of varying manufacturing parameters are carried out. The slicing performance of such diamond wire saws is evaluated and compared. The experimental results show that the developed saw using the photosensitive resin has a very good performance in slicing silicon ingots. By the comparison between the developed diamond wire saw and the electroplated diamond wire saw, the surface smoothness of the workpiece is better than that by the latter.
\end{abstract}

\section{Introduction}

For cutting silicon material, diamond wire saws or fixed abrasive wire saws have been attracting much attention in the community due to their many advantages [1-3]. For example, their kerf loss is small, which can improve the utilization of materials, and they are particularly attractive for machining expensive, hard, and brittle materials. The key technical challenge for diamond wire saw slicing of hard and brittle materials is the machined material's surface integrity, including roughness and subsurface damage [4]. Further study is very necessary in this area. In the past decade, several major technical developments in diamond wire saw machining have emerged. Recently, some researchers, for example, Clark, Sugawara, Peng, and Furutani, have investigated diamond wire saws [5-9]. Three basic categories of diamond wire saw can be distinguished according to the kind of bonding material employed: metallic bonding materials, organic bonding materials, and resin bonding materials.

This paper proposes a technology for developing diamond wire saw with photosensitive resin, based on our previous research results $[8,9]$. According to the characteristics of the photosensitive resin, we develop different bonding agents for a diamond wire saw. High-strength piano wires and polyethylene wires are selected as the core wire. According to the manufacturing process of this new diamond wire saw, a manufacturing machine has been designed. Some diamond wire saws are produced using different raw materials. A series of cutting experiments with different wire saws are carried out. A novel diamond wire saw is developed by using ultraviolet curing technology. High-strength piano wires and polyethylene wires are selected as wire cores, and photosensitive resin is used as the binder. The problem of wire saw strength is mathematically formulated, and the effective parameters are analyzed. Mathematical analysis and optimization method are necessary in this issue $[10,11]$. The surface morphology is analyzed for the developed diamond wire saw. A series of cutting experiments with different saws of varying manufacturing parameters are carried out. The slicing performance of such diamond wire saws is evaluated and compared in this paper. 


\section{Ultraviolet Curing Process}

2.1. Composition Materials. The main composition materials for the manufacture of the new diamond wire saw are photosensitive resin, core wire, and abrasive [12-23]. The photosensitive resin plays a vital role in the performance of the diamond wire saw. It is used as the binder of the diamond wire saw and is composed of epoxy acrylate resin, an appropriate quantity of preformed polymer, active diluent, photoinitiator, and other additives. After referring to the vast domestic and foreign technical literature on the manufacture of wire saws, a lot of resin-modified experiments have been done in order to improve its bond strength. Based on performance testing of several resins, their softness, tensile strength, and their film properties, two kinds of homemade photosensitive resin, epoxy acrylate and modified epoxy acrylate, were selected as the binder for the manufacture of the new diamond wire saw.

Diamond is the best abrasive for grinding hard brittle materials in general, for example, optical glass, ceramics, gems, stones, and so forth. Nickel-plated diamond surfaces have more roughness, and this can improve the bonding strength with the resin. The reason is that the material wetting performance between the diamond and the resin is changed [24]. Basic adhesion experiments between the resin and three types of diamonds were made. The diamonds are ordinary RVG diamond without nickel plating and RVG diamond with nickel plating, of weight gains $30 \%$ and $50 \%$. The results show that RVG diamond with nickel plating weight gain $50 \%$ has a higher bonding strength with the resin $[25,26]$.

During the cutting process, the wire saw is always maintained in a tension state, which is generally controlled in $20 \sim 30 \mathrm{~N}$ [5]. In order to meet the cutting conditions, the tensile strength and toughness of the wire saw should be higher. In the experiment, the piano wire and polyethylene wire are selected as the core wire $[27,28]$.

2.2. Formulation of Diamond Wire Saws. For the experiments, the core wire diameter of the new diamond wire saw is $\Phi=0.2 \mathrm{~mm}$. According to preliminary findings [25-28], the abrasive layer theoretical thickness is approximately $0.04 \mathrm{~mm}$, and thus the abrasive particle size is in the range $50 \sim 40 \mu \mathrm{m}$. Relative to the curing level and the height of the abrasive protrusion, the abrasive concentration in the abrasive layer was set at $100 \%$, which means that if the abrasive is ordinary RVG diamond, the diamond content per unit volume is $0.88 \mathrm{~g} / \mathrm{cm}^{3}$.

2.3. Manufacturing Process. Automatic control is applied in the manufacturing process of the fixed-abrasive diamond wire saw, which is designed in a coating machine. The coating machine is made up of a supply spool, a cleaning system, a tensioning system, an abrasive supply system, a UV-curing furnace, and a receiving spool. The manufacturing process consists of the following steps. Firstly, an ultrafine diamond abrasive plated with nickel, and the ultraviolet-curing resin should be mixed and churned up well. Then, it is injected into a coating cup by air pressure. Secondly, the core wire is

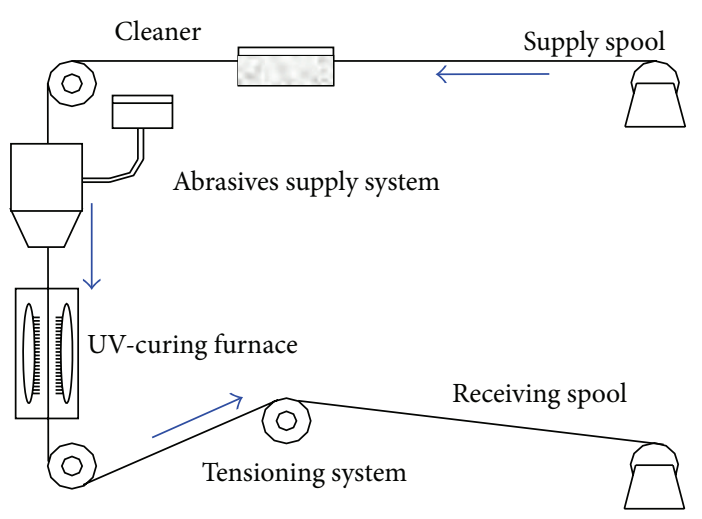

(a)

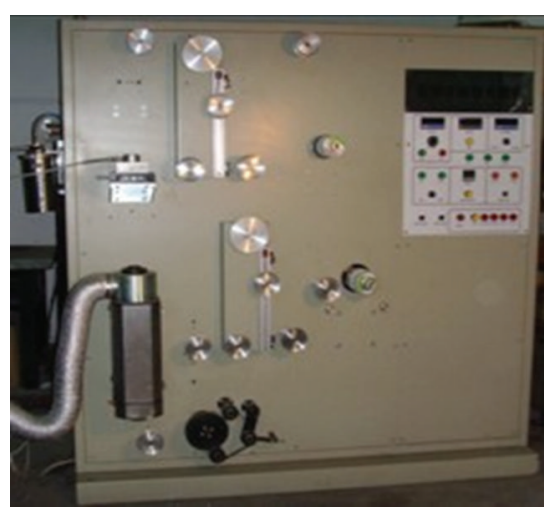

(b)

FIGURE 1: The wire saw manufacturing process and curing oven.

pretreated in our home-made solution. Then the core wire is installed on the coating machine. It goes through the supply spool, tensioning system, abrasive supply system, UV-curing furnace, and receiving spool. Thirdly, the core wire is coated with the abrasive solution in the coating cup. In succession, the abrasive layer is cured by ultraviolet light in a UV-curing furnace. Finally, the diamond wire saw is executed in the coating machine. Figure 1(a) shows the basic manufacturing process of the coating technique. In order to ensure the stability of the diamond wire saw production process, the diamond wire saw manufacturing machine was designed and manufactured according to the appropriate characteristics and technical requirements of the wire saw manufacturing process. Figure $1(\mathrm{~b})$ is the curing oven for the new diamond wire saw manufacturing. Figure 2 shows a photo of the new diamond wire saw, with image contrast enhancement by histogram smoothing [29].

\section{Evaluation Parameters}

Usually, to evaluate wire saw cutting performance, the parameters are its cutting efficiency, service life, and workpiece machining quality. In certain conditions, the cutting efficiency and service life are the main factors that determine the machining performance of wire saw. For the sake of evaluating the machining properties of the new diamond 


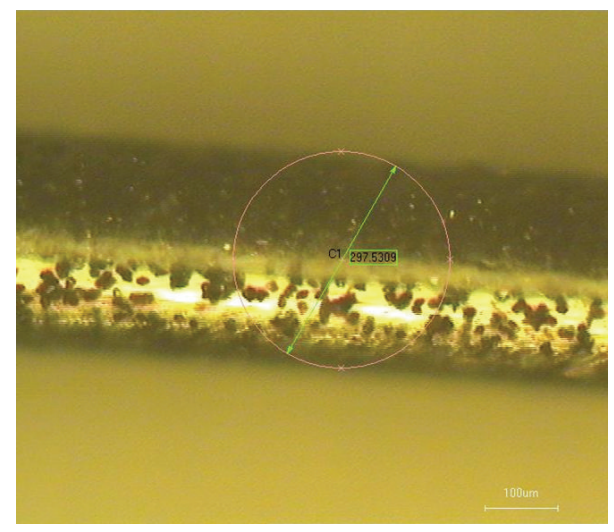

Figure 2: Microvision of a diamond wire saw $(\times 500)$.

wire saw, the material removal rate $M$ (MRR) and wearing resistance rate $W$ (WRR) are redefined in this paper. The material removal rate $M$ is defined as the average volume of material removed from the workpiece per unit time and reflects the efficiency of wire saw machining:

$$
M=\frac{V}{t},
$$

where $V$ is the total volume $\left(\mathrm{mm}^{3}\right)$ of material removed in the cutting process and $t$ is the cutting time (minute). The wearing resistance rate $W$ is defined as the ratio of the material removal volume to the weight loss of the wire saw. It reflects the durability of the saw. A greater value of $W$ reflects better wearing resistance of the wire saw and vice versa:

$$
W=\frac{V}{\Delta M}=\frac{V}{m_{i}-m_{f}},
$$

where $V$ is the total volume of workpiece material removed $\left(\mathrm{mm}^{3}\right)$ in the cutting process, $\Delta M$ is the weight loss of wire saw $(\mathrm{g}), m_{i}$ is the initial weight $(\mathrm{g})$ of the wire saw, which is weighed before the cutting process, and $m_{f}$ is the final weight (g) of the wire saw which is weighed after the cutting process.

\section{Impact of Ingredients}

4.1. Experimental Conditions. The processing performance of the wire saw is the ultimate test of whether the choice of material is reasonable. For estimating the processing performance of the newly developed diamond wire saw, some slicing experiments were done. The slicing technology conditions are showed in Table 1. The slicing experiment for slicing workpiece, poly-silicon ingot, was carried out on the WXD170 reciprocating cutting machine by using various new diamond wire saws.

4.2. Photosensitive Resin. The properties of the photosensitive resin depend on the performance of the oligomers and its composition. Adding a monomer can modify the photosensitive resin, which can affect the performance of the new diamond wire saw to a certain extent. In this
TABLE 1: Experimental conditions in the slicing process.

\begin{tabular}{lc}
\hline Item & Value \\
\hline Wire sawing machine & WXD170 \\
Workpiece & $\Phi 44 \mathrm{~mm}$ silicon ingot \\
Wire saw diameter $(\mathrm{mm})$ & $\Phi 0.28$ \\
Wire saw line speed $(\mathrm{m} / \mathrm{min})$ & 2.5 \\
Wire saw feed speed $(\mathrm{mm} / \mathrm{min})$ & 0.375 \\
Workpiece rotate speed $(\mathrm{rpm})$ & 3.5 \\
Wire tension $(\mathrm{MPa})$ & 0.2 \\
Coolant & tap water \\
\hline
\end{tabular}

TABLE 2: The experimental results.

\begin{tabular}{lcc}
\hline Wire saw type & $\begin{array}{c}\text { Material removal rate } \\
M\left[\mathrm{~mm}^{3} / \mathrm{min}\right]\end{array}$ & $\begin{array}{c}\text { Wearing resistance } \\
\text { rate } W\left[\mathrm{~mm}^{3} / \mathrm{g}\right]\end{array}$ \\
\hline $\begin{array}{l}\text { Photosensitive resin } \\
\text { OOP }\end{array}$ & 395 & 6.89 \\
MOP & 538 & 7.19 \\
Diamond abrasives & & \\
MOP & 535 & 7.12 \\
MNP & 551 & 7.24 \\
Core wire & & \\
MNP & 540 & 7.20 \\
MNL & 376 & 7.32 \\
\hline
\end{tabular}

experiment, epoxy acrylate and epoxy acrylate blended with 5\% SR351 monomer were selected as the binder for the manufacture of diamond wire saw the by with OOP and MOP, respectively. Under the technological conditions described above, the slicing experiments were carried out to investigate the material removal rate $M$ and wearing resistance rate $W$ of the new diamond wire saw. The experimental results are shown in Table 2.

It can be seen that the wearing resistance rate of wire saw sample 2 is increased about $36 \%$. Analyzed from the perspective of materials science, the hardness of the resin layer increases when the monomer is added. This improves the wear resistance of the resin layer and then improves the WRR of the diamond wire saw. When the resin layer hardness increases, the abrasive inlaid in the resin layer does not come off easily. From Table 2, we can see that the material removal rate of workpiece cutting by MOP increases about $4.3 \%$.

4.3. Diamond Abrasives. The cutting process of a wire saw is a micropolishing process by the diamond abrasive which is embedded in the resin layer. The bonding strength between the diamond grit and the resin layer determines the cutting performance of a diamond wire saw. Based on these experimental results, two kinds of diamond, that is, ordinary RVG diamond without nickel plating and RVG diamond with nickel plating weight gain 50\%, are adopted for manufacturing the developed diamond wire saw and labeled by MOP and MNP, respectively. Similarly, the slicing experiments are carried out under the described above technological conditions. The experimental results are shown in Table 2. It 
is seen that nickel plating on the diamond can increase the bonding strength of the diamond and resin. Therefore, the higher the bond strength of the resin and diamond, the higher the cutting ability of the diamond wire saw gained during cutting process.

The wear failure form of a diamond wire saw is that the abrasive resin layer is broken and off the core wire. Figure 3 shows a typical microscope surface topography of a worn diamond wire saw. It can be seen that the diamond abrasive is broken (Figure 3(a)) and worn away from the resin layer (Figure 3(b)).

4.4. Core Wire. During the cutting process, the wire saw is always maintained in a state of tension. It will be bended due to the workpiece feed force. So the strength of the wire saw includes tensile strength and bending strength. The wire tensile force can be calculated as follows:

$$
F_{1}=F_{0}+\Delta F
$$

where $F_{1}$ is the wire tensile force, $F_{0}$ is the wire initial tensile force, and $\Delta F$ is the change amount of the wire tensile force, which is calculated based on the following formula (4):

$$
\Delta F=E A \varepsilon,
$$

where $A$ is the cross-sectional area of wire, $E$ is the modulus of elasticity, $\varepsilon$ is the axial strain of wire.

The tensile stress of wire saw is defined as:

$$
\sigma_{1}=\frac{F_{1}}{A}=\frac{F_{0}}{A}+E\left(\sqrt{1+\operatorname{tg}^{2} \alpha}-1\right)
$$

where $\alpha$ is the angle of wire saw during the cutting process.

The bending stress of wire saw is defined as

$$
\sigma_{2}=E \frac{d}{D}
$$

where $d$ is the diameter of wire and $D$ is the diameter of guide pulley during the cutting process.

If we use comprehensive tensile stress to describe the strength of the wire saw and take a safety factor in order to ensure that the wire saw during the cutting process is not pulled off, the comprehensive tensile stress is required to meet the following relationship:

$$
\sigma>k\left(\sigma_{1}+\sigma_{2}\right)=k E\left(\frac{F_{0}}{E A}+\sqrt{1+\operatorname{tg}^{2} \alpha}+\frac{d}{D}-1\right),
$$

where $\sigma$ is the comprehensive tensile stress, $\sigma_{1}$ is the tensile stress, $\sigma_{2}$ is the bending stress, $k$ is the safety factor, here $1.1, F_{0}$ is the initial tension, here $35 \mathrm{~N}, E$ is the modulus of elasticity, here about $200 \mathrm{GP}, d$ is the diameter of the wire, here $0.2 \mathrm{~mm}$, and $D$ is the diameter of the guide pulley, here $250 \mathrm{~mm}$.

The comprehensive tensile stress of wire is about $1230 \mathrm{Mpa}$ by a calculation. As long as the material can meet the strength requirements of the core wire, it can be theoretically used to make the wire saw. The material for a wire saw is metal, generally. Beyond the conventional, we not only chose metal materials but also selected nonmetallic materials to

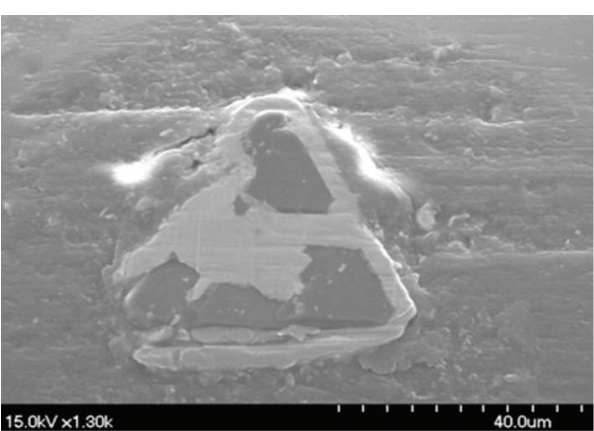

(a)

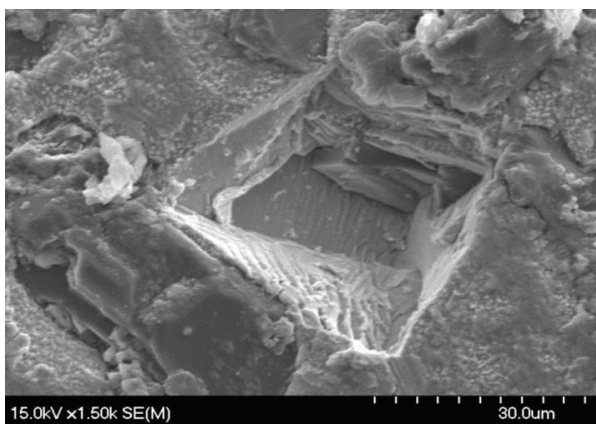

(b)

FIGURE 3: The typical micrographs of worn wire saws.

TABLE 3: Choices of the core wire.

\begin{tabular}{lccc}
\hline Core wire & $\begin{array}{c}\text { Diameter } \\
(\mathrm{mm})\end{array}$ & $\begin{array}{c}\text { Tensile stress } \\
(\mathrm{MPa})\end{array}$ & Manufacturer \\
\hline Piano wire & $\Phi 0.2$ & $2820 \pm 100$ & $\begin{array}{c}\text { Korea Steel Ltd. } \\
\text { Ningbo Dacheng } \\
\text { Polyethylene } \\
\text { wire }\end{array}$ \\
\hline
\end{tabular}

make the core wire in the experiment. The core wire material is illustrated in Table 3 .

We manufacture the new diamond wire saw using piano wire and polyethylene wire and label these two types by MNP and MNL, respectively. Similarly, the slicing experiments are carried out under the technological conditions described above. The experimental results are shown in Table 2. The results show that the wearing resistance rate of wire labeled MNL is lower. The reason is that the elongation of polyethylene wire is higher than that of piano wire, which makes the abrasive resin layer flake off the core wire easily. Since the abrasive resin layer is so easy to flake off and its wearing resistance rate is lower, the material removal rate of it is higher. The reason may be that some of the abrasives flaked from resin layer are involved in the cutting.

\section{Comparative Experiments on Surface Roughness}

On the basis of these studies of the raw materials and manufacturing processes of the diamond wire saw and the 


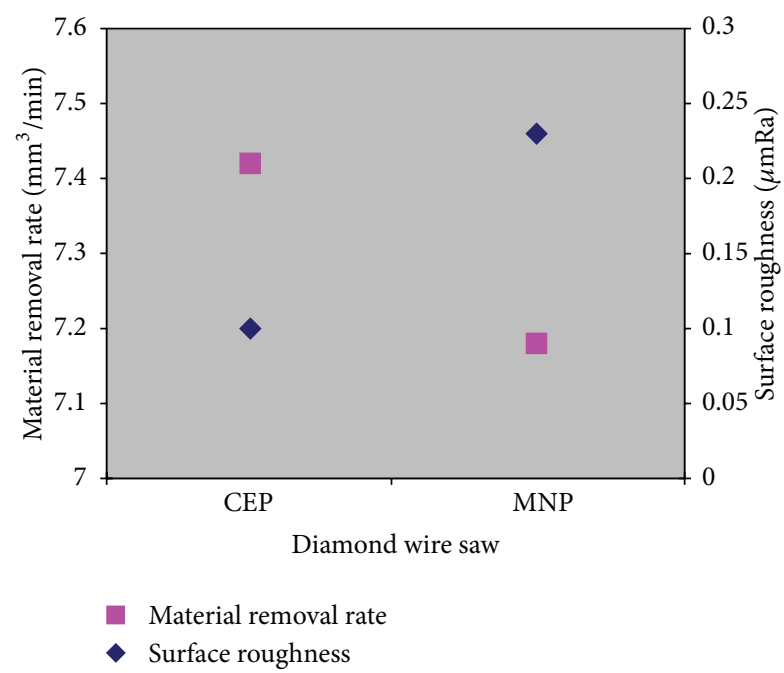

FIgURE 4: The MRR and average surface roughness Ra of workpiece.

new diamond wire saw was manufactured with piano wire, diamond with nickel plating, and modified epoxy acrylate. In order to compare the cutting performance of the new diamond wire saw with other diamond wire saws, cutting experiments were carried out under the conditions listed in Table 1. The commercial electroplated diamond wire saw was selected as the reference wire saw, labeled by CEP. Figure 4 shows the material removal rate and average surface roughness Ra. The surface roughness was measured by the Mahr Perthometer S2 surface roughness measuring instrument. It was measured along the radial direction of the workpiece. The average surface roughness and the material removal rate of the new diamond wire saw are lower than that of the commercial diamond wire saw. In the slicing process, due to the characteristics of the resin itself, its consolidation capacity with the abrasive grit is weaker than that obtained by electroplating, so the abrasive resin layer was broken to pieces easily, which makes the slicing performance of the new diamond wire saw lower. But on the other hand, this small broken abrasive resin layer works as a microblade, cutting on the surface of the workpiece because of the vibration of the wire. It assists the polishing of the surface and makes the surface roughness lower.

\section{Conclusion}

This paper has exploited the techniques of a diamond wire saw based on an ultraviolet curing method. A wire saw manufacturing machine was designed and manufactured according to the characteristics and technical requirements of the manufacturing process. We found that the characteristics of the photosensitive resin and abrasive grit affect the performance of the new diamond wire saw. A modified epoxy acrylate and diamond with nickel were applied for the manufacture of this new wire saw. The cutting performance is evaluated and compared. The experimental results show that the diamond wire saw made with the photosensitive resin has a good performance in cutting poly-silicon ingots. It demonstrates that the new method is feasible. For the sake of evaluating the machining properties of the developed diamond wire saw, the material removal rate and wearing resistance rate were redefined. Surface roughness obtained by the new diamond wire saw is better than that by the usual electroplated wire saw.

\section{Acknowledgments}

The work was supported by the National Natural Science Foundation of China (51075367) and Natural Science Foundation of Zhejiang Province (Y1090931).

\section{References}

[1] C. Chung, C. S. Korach, and I. Kao, "Experimental study and modeling of lapping using abrasive grits with mixed sizes," Journal of Manufacturing Science and Engineering, vol. 133, no. 3, Article ID 031006, 2011.

[2] M. Fathi, A. Mefoued, A. Messaoud, and A. Boukennous, "Costeffective photovoltaics with silicon material," Physics Procedia, vol. 2, pp. 751-757, 2009.

[3] E. Teomete, "Investigation of long waviness induced by the wire saw process," Proceedings of the Institution of Mechanical Engineers B, vol. 225, no. B7, pp. 1153-1162, 2011.

[4] J. Sugawara, H. Hara, and A. Mizoguchi, "Development of fixedabrasive-grain wire saw with less cutting loss," SEI Technical Review, vol. 58, no. 6, pp. 7-11, 2004.

[5] W. I. Clark, A. J. Shih, C. W. Hardin, R. L. Lemaster, and S. B. McSpadden, "Fixed abrasive diamond wire machining-part I: process monitoring and wire tension force," International Journal of Machine Tools and Manufacture, vol. 43, no. 5, pp. 523-532, 2003.

[6] P. Q. Ge, L. Zhang, W. Gao, and Z. C. Liu, "Development of endless diamond wire saw and sawing experiments," Materials Science Forum, vol. 471-472, pp. 481-484, 2004.

[7] K. Furutani and Y. Murase, "Fabrication of Wire Saw with Patterned Hard Bumps by Electrical Discharge Machining with Powder Suspended in Working Oil," in Proceedings of the 41st CIRP Conference on Manufacturing Systems, pp. 361-364, Tokyo, Japan, 2008.

[8] W. Peng, F. Q. Liu, and C. Y. Yao, "Research on the ultravioletcuring resin wire saw," in Proceedings of the International Technology and Innovation Conference (ITIC '06), vol. 524, pp. 2347-2350, Hangzhou, China, November 2006.

[9] W. Peng, C. Y. Yao, X. Lv, F. Q. Liu, T. Gao, and J. L. Yuan, "Experimental study on new bonding materials for developing nano-grinding plates," Key Engineering Materials, vol. 329, pp. 489-494, 2007.

[10] Y. Zheng, S. Chen, Y. Lin, and W. Wang, "Bio-inspired optimization of sustainable energy systems: a review," Mathematical Problems in Engineering, vol. 2013, Article ID 354523, 12 pages, 2013.

[11] Y. Zheng, H. Shi, J. Xue, and S. Chen, "Formal calculation and invariant-based validation establish dependable algorithmic programs," China Communications, vol. 8, no. 4, pp. 58-64, 2011.

[12] H. Wu and S. N. Melkote, "Study of ductile-to-brittle transition in single grit diamond scribing of silicon: application to wire sawing of silicon wafers," Journal of Engineering Materials and Technology, vol. 134, no. 4, 2012. 
[13] E. Teomete, "Roughness damage evolution due to wire saw process," International Journal of Precision Engineering and Manufacturing, vol. 12, no. 6, pp. 941-947, 2011.

[14] G. Skomedal, E. Ovrelid, S. Armada, and N. Espallargas, "Effect of slurry parameters on material removal rate in multi-wire sawing of silicon wafers: a tribological approach," Proceedings of the Institution of Mechanical Engineers J, vol. 225, no. J10, pp. 1023-1035, 2011.

[15] T. Liedke and M. Kuna, "A macroscopic mechanical model of the wire sawing process," International Journal of Machine Tools and Manufacture, vol. 51, no. 9, pp. 711-720, 2011.

[16] Z. Li, Z. Pei, and P. Funkenbusch, "Machining processes for sapphire wafers: a literature review," Proceedings of the Institution of Mechanical Engineers B, vol. 225, no. B7, pp. 975-989, 2011.

[17] A. Bidiville, K. Wasmer, J. Michler, P. M. Nasch, M. Van Der Meer, and C. Ballif, "Mechanisms of wafer sawing and impact on wafer properties," Progress in Photovoltaics, vol. 18, no. 8, pp. 563-572, 2010.

[18] S. Bhagavat, J. C. Liberato, C. Chung, and I. Kao, "Effects of mixed abrasive grits in slurries on free abrasive machining (FAM) processes," International Journal of Machine Tools and Manufacture, vol. 50, no. 9, pp. 843-847, 2010.

[19] Z. J. Pei, G. R. Fisher, and J. Liu, "Grinding of silicon wafers: a review from historical perspectives," International Journal of Machine Tools and Manufacture, vol. 48, no. 12-13, pp. 1297-1307, 2008.

[20] S. Bhagavat and I. Kao, "A finite element analysis of temperature variation in silicon wafers during wiresaw slicing," International Journal of Machine Tools and Manufacture, vol. 48, no. 1, pp. 95106, 2008.

[21] S. Bhagavat and I. Kao, "Ultra-low load multiple indentation response of materials: in purview of wiresaw slicing and other free abrasive machining (FAM) processes," International Journal of Machine Tools and Manufacture, vol. 47, no. 3-4, pp. 666-672, 2007.

[22] M. Mizuno, T. Iyama, S. Kikuchi, and B. Zhang, "Development of a device for measuring the transverse motion of a saw-wire," Journal of Manufacturing Science and Engineering, vol. 128, no. 3, pp. 826-834, 2006.

[23] S. Bhagavat and I. Kao, "Theoretical analysis on the effects of crystal anisotropy on wiresawing process and application to wafer slicing," International Journal of Machine Tools and Manufacture, vol. 46, no. 5, pp. 531-541, 2006.

[24] J. Y. Gu, Adhesive Bonding Theory and Basic, Science Press, Beijing, China, 2003.

[25] F. Liu, Research on manufacturing technology of ultravioletcuring diamond wire saw [Ph.D. thesis], Zhejiang University of Technology, 2009.

[26] W. Peng, F. Q. Liu, and C. Y. Yao, "Surface modification of diamond to improve machining properties of ultraviolet-curing wire saw," Advanced Materials Research, vol. 69-70, pp. 24-28, 2009.

[27] F. Liu, C. Yao, and W. Peng, "Key factors in ultraviolet-curing wire saw," in Proceedings of the International Conference on Integration and Commercialization of Micro and Nanosystems, pp. 1283-1288, January 2007.

[28] C. Y. Yao, W. Peng, M. H. Wang, and F. Q. Liu, "The diamond wire saw with a nonmetallic core," Advanced Materials Research, vol. 69-70, pp. 328-332, 2009.

[29] N. M. Kwok, X. Jia, D. Wang, S. Y. Chen, Q. P. Ha, and G. Fang, "Image contrast enhancement based on histogram smoothing and continuous intensity relocation," in Proceedings of the $3 \mathrm{rd}$ International Congress on Image and Signal Processing (CISP '10), pp. 1-5, Yantai, China, October 2010. 


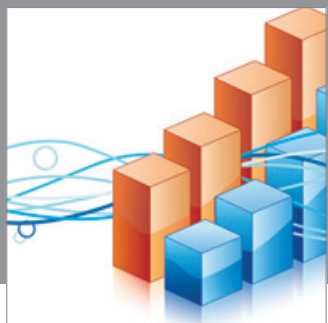

Advances in

Operations Research

mansans

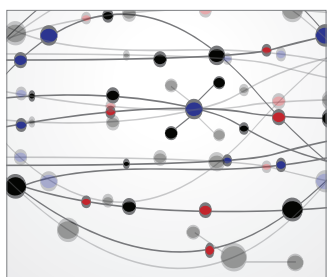

The Scientific World Journal
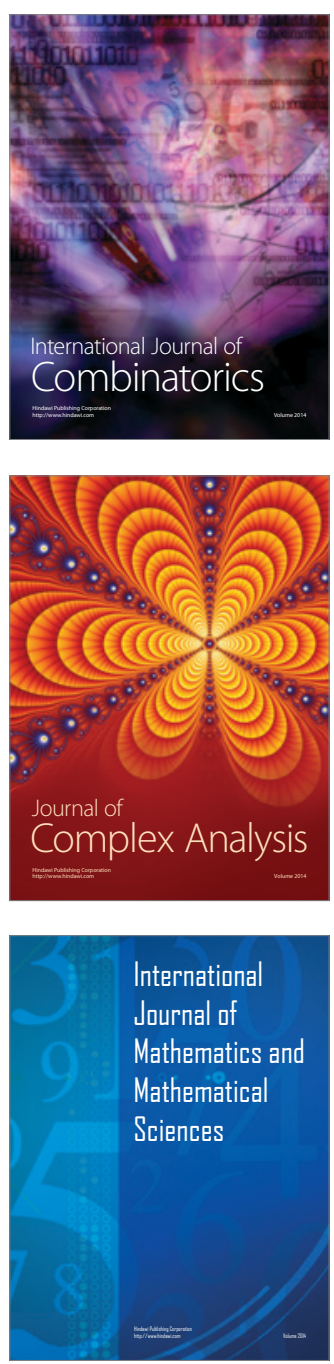
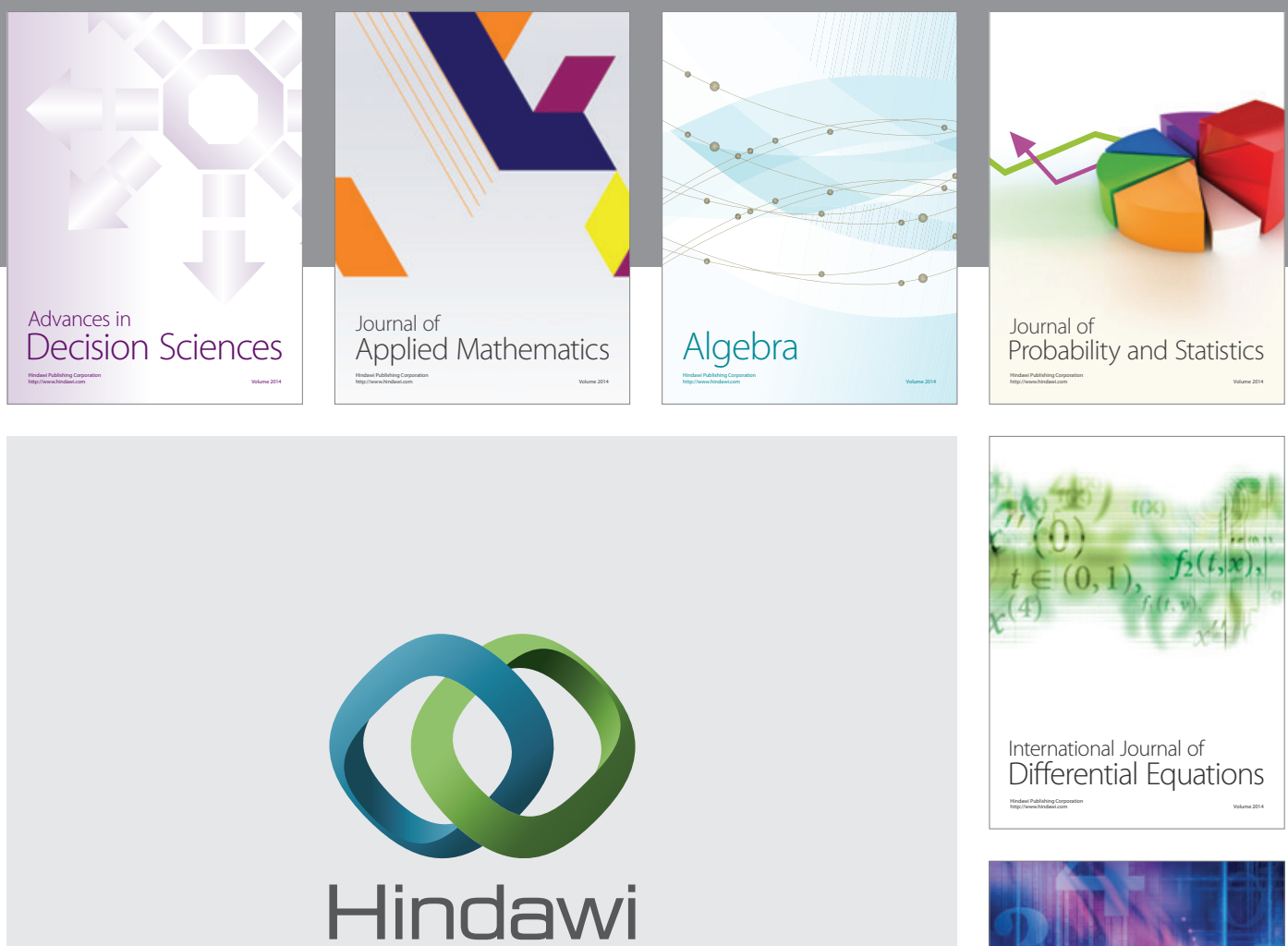

Submit your manuscripts at http://www.hindawi.com
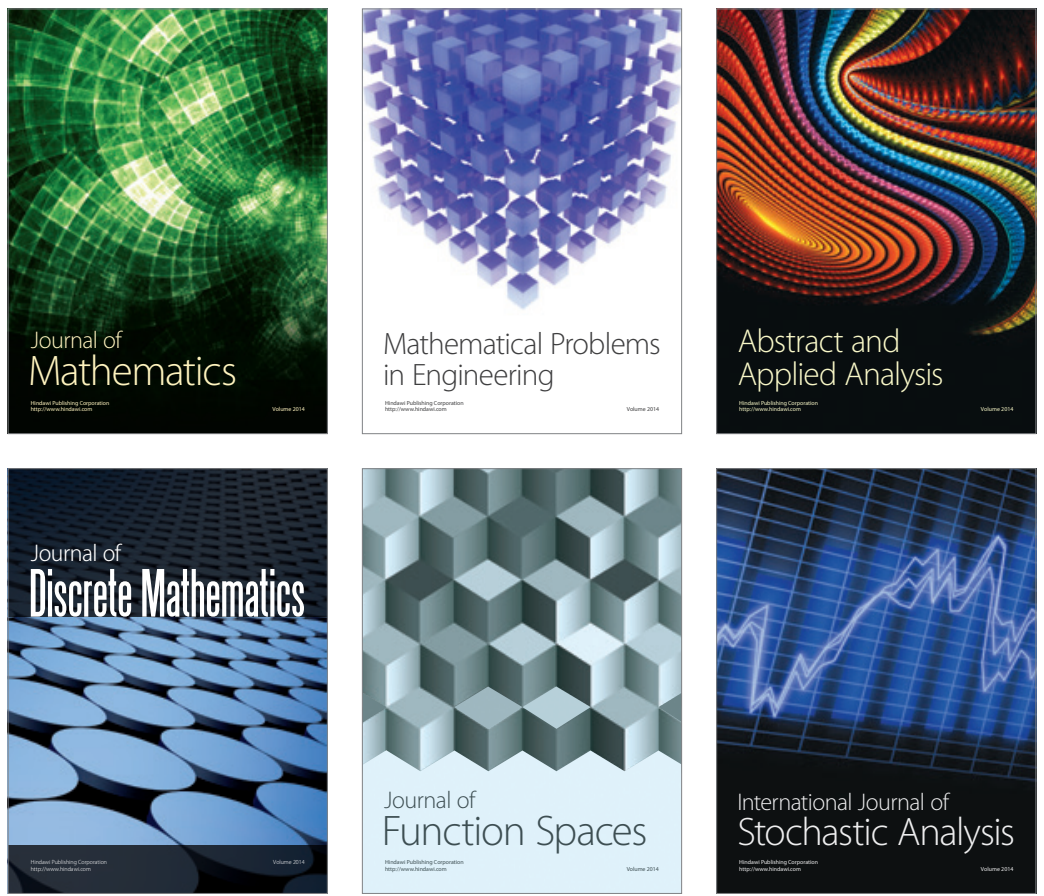

Journal of

Function Spaces

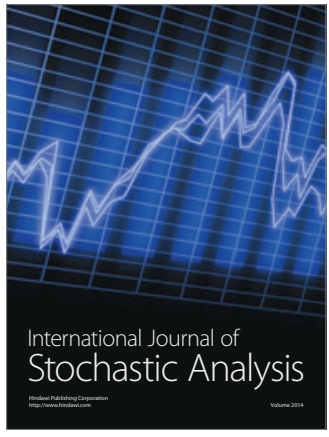

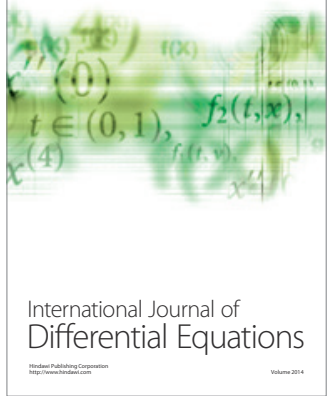
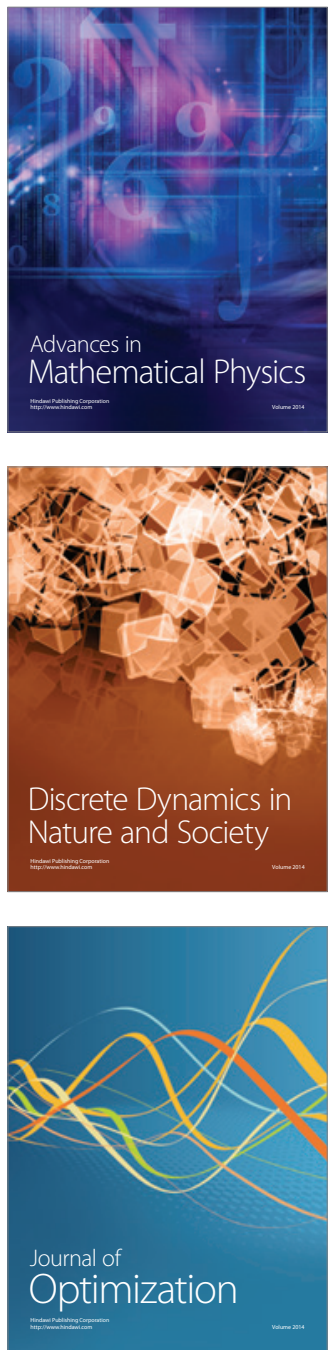